\title{
InfluênCIA da Chuva na EficÁCIA do Glyphosate em MistuRA COM Adj UVANTES na DessecaÇÃo de Plantas Daninhas ${ }^{1}$
}

\author{
Influence of Rain on the Efficacy of Glyphosate in Mixture with Adjuvants in Weed Desiccation
}

PEDRINHO JUNIOR, A.F.F ${ }^{2}$, PIVA, F.M..$^{3}$, MARTINI, G. ${ }^{3}$, FELICI, G.V. ${ }^{3}$ e DURIGAN, J.C. ${ }^{4}$

\begin{abstract}
RESUMO - Com o objetivo de estudar a influência do momento da chuva após a aplicação do herbicida glyphosate isolado e em mistura com adjuvantes na dessecação de plantas daninhas, foram instalados dois experimentos na Fazenda Experimental de Ensino e Pesquisa da Faculdade de Ciências Agrárias e Veterinárias, UNESP - campus de Jaboticabal-SP, em duas épocas: inverno de 2000 (junho - agosto) e verão de 2001 (janeiro-março). Os experimentos foram instalados no delineamento experimental de blocos ao acaso, em arranjo fatorial 4 (tratamentos herbicidas) x 5 (períodos livres de chuva simulada) +1 , com quatro repetições. Os tratamentos consistiram da combinação de glyphosate SAqC (360 g e.a. ha ${ }^{-1}$ ) isolado ou adicionado de uréia (50 $\mathrm{g} \mathrm{L}^{-1}$ de calda) ou óleo vegetal $\left(100 \mathrm{ml} \mathrm{L}^{-1}\right.$ de calda) ou sulfato de amônio (100 $\mathrm{g} \mathrm{L}^{-1}$ de calda), com cinco períodos de chuva simulada $(1,2,4$, 6 e $>48$ horas após a aplicação), além de uma testemunha. A chuva foi simulada com um sistema de irrigação por aspersão, e a quantidade aplicada variou entre 18 e $19 \mathrm{~mm}$. Em ambas as épocas a chuva foi prejudicial à ação do glyphosate, principalmente nos menores períodos livres de chuva após a aplicação. Os sintomas de fitointoxicação apareceram mais rapidamente no verão. A utilização de adjuvantes na calda de pulverização não beneficiou o desempenho do herbicida glyphosate no controle das plantas daninhas, no inverno. A adição de uréia (50 $\left.\mathrm{g} \mathrm{L}^{-1}\right)$ é uma boa alternativa para o controle de plantas daninhas, no verão, em situações sujeitas à chuva até duas horas após a aplicação.
\end{abstract}

Palavras-chave: controle de plantas daninhas, chuva simulada, clima.

\begin{abstract}
The objective of this research was to evaluate the effects of the moment of rain on the activity of the herbicide glyphosate, applied alone and in combination with surfactants, on two growing seasons (winter and summer); at FCAV-UNESP Experimental Station, JaboticabalSP, Brazil,, during 2000/2001. The winter experiment was installed from June to August 2000 and the summer one from January to March 2001. The treatments were glyphosate SAqC (360 g e.a. $\left.\mathrm{ha}^{-1}\right)$, alone or in combination with urea $\left(50 \mathrm{~g} \mathrm{~L}^{-1}\right)$, vegetable oil $\left(100 \mathrm{ml} \mathrm{L}^{-1}\right)$ or ammonium sulfate (100 $\left.\mathrm{g} \mathrm{L}^{-1}\right)$, and five periods of simulated rainfall (1, 2, 4, 6 or 48 hours after application) and a check treatment. The experimental design was set up in a randomized block factorial, 5 (herbicides) $x 6$ (moment of rain) +1 (controls treatment), with four replications. The artificial rain was provided by a top irrigation system supplying 18-19 mm rain during one hour. The artificial rain reduced the glyphosate action, mainly in the earlier periods. The herbicide symptoms appeared sooner in the summer trial. The use of surfactants in the spray mixture did not improve the performance of glyphosate on weed control during the winter. The addition of urea (50 $\left.\mathrm{g} \mathrm{L}^{-1}\right)$, is a good alternative for weed control during summer, when rainfall is expected after the application.
\end{abstract}

Key words: weed control, rainfastness, climate.

1 Recebido para publicação em 1/3/2002 e na forma revisada em 7/8/2002.

Parte do trabalho de graduação do primeiro autor. <aimarpjr@zipmail.com.br>.

2 Eng.-Agrônomo, Mestrando em Agronomia, Área de concentração: Produção Vegetal. FCAV-UNESP, Rod. Prof. Paulo D. Castellane, km, 5, 14870-000 Jaboticabal-SP. ${ }^{3}$ Graduandos em Agronomia, Dep. de Fitossanidade, FCAV-UNESP, JaboticabalSP. ${ }^{4}$ Professor titular do Dep. de Fitossanidade, FCAV-UNESP, Jaboticabal-SP.

Planta Daninha, Viçosa-MG, v.20, n.2, p.263-271, 2002 


\section{INTRODUÇÃO}

A interferência das plantas daninhas é um dos fatores que mais afetam a produtividade de culturas anuais e perenes. Esse prejuízo ocorre principalmente devido à competição por luz, água, nutrientes e $\mathrm{CO}_{2}$ (Blanco et al., 1973), trazendo prejuízos financeiros para os agricultores, que perdem em produtividade e qualidade do produto final.

Um dos grupos de herbicidas mais vendidos no mundo é o dos inibidores de EPSPs, no qual está o glyphosate, com maior participação no mercado, pois são mais de 90 marcas comerciais com esse ingrediente ativo. Os inibidores de EPSPs perfazem $12 \%$ da venda global de herbicidas, sendo distribuídos em 119 países e somando mais de 150 marcas comerciais (Heap, 1997). Atualmente, é uma das moléculas mais utilizadas no Brasil, devido ao seu preço e à sua eficácia para grande número de espécies de plantas daninhas.

O glyphosate aplicado na parte aérea das plantas transloca-se, causando morte do sistema radicular e das estruturas reprodutivas de plantas perenes, como rizomas, bulbos e tubérculos. Possui coeficiente de partição octanol/água extremamente baixo $(-4,1)$, indicando que a molécula tem baixa afinidade por substâncias graxas e altíssima por água. Essa é uma das causas principais de sua absorção relativamente lenta, tornando a aplicação arriscada em épocas chuvosas e obrigando o fabricante a recomendar período sem chuvas de seis horas após a aplicação (Kruse et al., 2000). Outros fatores ambientais também podem influenciar a eficácia do produto para controle de plantas daninhas, como a temperatura, a luminosidade, a umidade do solo, a umidade relativa do ar e a ocorrência de geadas (Baird, 1971; Fawcett \& Davis, 1976).

Alguns trabalhos vêm sendo realizados na tentativa de aumentar a eficácia do glyphosate no controle de plantas daninhas (Durigan, 1993). Estudos mostram que a adição de surfatantes à calda pode melhorar o desempenho do produto, por meio do aumento da cobertura e retenção das gotas nas folhas e, conseqüentemente, da absorção foliar. Esses produtos aumentam a hidratação da cutícula, incrementando a difusão de glyphosate através desta (Ruiter \& Mainen, 1998).
A ocorrência de chuva após a aplicação, principalmente de herbicidas inibidores de EPSPs, tem se mostrado um grande problema para os agricultores que necessitam fazer manejo de plantas daninhas em épocas chuvosas (Pedrinho Junior, 2001). Jakelaitis et al. (2001) observaram que a chuva simulada uma hora após a aplicação anulou o efeito herbicida das formulações glyphosate WG, CS, Transorb, Zapp e Zapp QI no controle de Digitaria horizontalis. Estes autores ainda observaram diferenciação no controle de $D$. horizontalis quando a chuva foi simulada em períodos superiores a duas horas após a aplicação, mostrando as formulações Transorb, Zapp e Zapp QI melhor desempenho nessa situação. Pedrinho Junior et al. (2002) também notaram acentuada diferença entre formulações de herbicidas inibidores de EPSPs no controle de uma população daninha quando se simulou chuva até quatro horas após a aplicação, tendo a formulação glyphosate WG o pior desempenho em relação a glyphosate CS, Transorb e Zapp. Resultados semelhantes foram observados por Roman (2001), que descreveu pior desempenho da formulação glyphosate WG quando se simulou chuva até quatro horas após a aplicação para o controle de Brachiaria plantaginea, comparado aos resultados obtidos por glyphosate Transorb e glyphosate potássico.

A mistura do herbicida com algumas substâncias pode resultar em melhora no controle final das plantas daninhas e, talvez, minimizar o problema da chuva após a aplicação. Durigan (1992) relata que a mistura de uréia a $0,2 \%$ ou óleo vegetal a $2 \mathrm{~L} \mathrm{ha}^{-1}$ ao glyphosate proporciona bons resultados para o controle de capimcolonião, podendo-se reduzir a dosagem do herbicida. Carvalho (2000) afirma que nem sempre misturas de glyphosate com adjuvantes resultam em soluções sinérgicas, e em algumas vezes pode-se incorrer em antagonismo, comum na mistura de glyphosate com outros herbicidas. Existem relatos feitos por Poovaiah \& Leopold (1974), segundo os quais a adição de sulfato de amônio ou surfatante aos herbicidas linuron e simazina evita os possiveis efeitos antagônicos.

Estudos são realizados para que as recomendações garantam maior segurança ao agricultor quando utilizar esse tipo de herbicida, mesmo em épocas mais chuvosas, pois a 
reaplicação é uma prática que onera os custos de produção, demanda mais tempo de trabalho e aumenta a poluição ambiental. Além disso, os efeitos podem ser prejudicados pelo estresse das plantas, provocado pela primeira aplicação.

O presente trabalho teve por objetivo estudar a influência do momento da chuva simulada após a aplicação na eficácia do herbicida glyphosate isolado e em mistura com adjuvantes, no inverno e no verão.

\section{MATERIAL E MÉTODOS}

Foram instalados a campo, na Fazenda Experimental de Ensino e Pesquisa da Faculdade de Ciências Agrárias e Veterinárias UNESP, campus de Jaboticabal-SP, durante o período de junho de 2000 a março de 2001, dois experimentos, em duas épocas do ano (inverno de 2000 e verão de 2001). O clima da região, de acordo com a classificação de Köppen, é do tipo Cwa, ou seja, mesotérmico de inverno seco, com temperatura média do mês mais quente superior a $22^{\circ} \mathrm{C}$, e a do mês mais frio, superior a $18^{\circ} \mathrm{C}$. A cidade de Jaboticabal localiza-se na latitude de $21^{\circ} 15^{\prime} 22^{\prime \prime}$ e na longitude de $48^{\circ} 18^{\prime} 58^{\prime \prime}$, com altitude de 580 metros acima do nível do mar. O solo do local foi classificado, segundo Centurion (1998), como Latossolo Vermelho-Escuro, eutrófico, horizonte A moderado, textura muito argilosa e relevo suavemente ondulado.

Os experimentos foram instalados no delineamento experimental de blocos ao acaso em esquema fatorial de $4 \times 5+1$, sendo quatro adjuvantes e cinco períodos de chuva após a aplicação, com quatro repetições. As parcelas experimentais mediam $3,0 \mathrm{~m}$ de largura por $3,5 \mathrm{~m}$ de comprimento, no inverno, e 3,0 x 4,0 m, no verão. Para facilidade de visualização, os tratamentos testados, em ambas as épocas, são apresentados na Tabela 1.

Tabela 1 - Tratamentos com herbicida glyphosate utilizados no inverno e no verão e os horários que foram submetidos à chuva simulada após a aplicação, para o controle de plantas daninhas em pós-emergência. Jaboticabal-SP, 2000/2001

\begin{tabular}{|c|c|c|}
\hline Tratamento & $\begin{array}{l}\text { Dosagem } \\
\left(\text { g e.a. }^{-1}{ }^{-1}\right)\end{array}$ & $\begin{array}{c}\text { Intervalo, em } \\
\text { horas, entre a } \\
\text { aplicação e a } \\
\text { chuva simulada }\end{array}$ \\
\hline glyphosate + uréia & $360+50 \mathrm{~g} \mathrm{~L}^{-1}$ & $1,2,4,6 \mathrm{e}>48$ \\
\hline glyphosate + óleo vegetal & $360+100 \mathrm{ml} \mathrm{L}^{-1}$ & $1,2,4,6$ e $>48$ \\
\hline glyphosate + sulfato de amônio & $360+100 \mathrm{~g} \mathrm{~L}^{-1}$ & $1,2,4,6$ e $>48$ \\
\hline glyphosate & 360 & $1,2,4,6 \mathrm{e}>48$ \\
\hline Testemunha & sem herbicida & -- \\
\hline
\end{tabular}

O herbicida utilizado foi o glyphosate, na formulação solução aquosa e concentração de 360 g e.a. $\mathrm{L}^{-1}$, sempre aplicado na pós-emergência das plantas daninhas. Nas aplicações utilizou-se um pulverizador costal, à pressão constante (mantida por ar comprimido) de $30 \mathrm{lbf} \mathrm{pol}^{-2}$, munido de barra com seis bicos DG 11002, espaçados de $50 \mathrm{~cm}$, totalizando 3,0 metros a largura de faixa de aplicação.

Na Tabela 2 são apresentadas as plantas daninhas predominantes, o comprimento e a intensidade de infestação (cobertura da área) em cada um dos experimentos, nas duas épocas do ano. Os dados referentes às condições climáticas, nos diferentes horários de aplicação e épocas do ano, para cada experimento, são apresentados na Tabela 3.

No inverno e no verão, a chuva foi simulada com um sistema de irrigação por aspersão. A quantidade de chuva variou entre 18 e $19 \mathrm{~mm}$, molhando todas as parcelas de uma só vez.

Tabela 2 - Plantas daninhas presentes, com respectivos comprimento e porcentagem de cobertura da área no momento da aplicação, em cada um dos experimentos nas duas épocas do ano. Jaboticabal-SP, 2000/2001

\begin{tabular}{|l|l|l|l|r|}
\hline \multicolumn{2}{|c|}{ Época do ano } & \multicolumn{1}{|c|}{ Planta Daninha } & \multicolumn{1}{c|}{ Comprimento da haste } & $\begin{array}{c}\% \text { de } \\
\text { cobertura }\end{array}$ \\
\hline \multirow{3}{*}{ Experimento } & \multirow{2}{*}{ Inverno } & $\begin{array}{l}\text { Brachiaria plantaginea (Link.) Hitch. } \\
\text { Brachiaria decumbens Stapf. }\end{array}$ & $0,3 \mathrm{~m}$ de comprimento (com sementes) & 70 \\
\cline { 2 - 6 } & \multirow{2}{*}{ Verão } & Brachiaria plantaginea (Link.) Hitch. & $0,55 \mathrm{~m}$ de comprimento (sem sementes) & 25 \\
& & Brachiaria decumbens Stapf. & $0,45 \mathrm{~m}$ de comprimento (com sementes) & 75 \\
20
\end{tabular}


Tabela 3 - Dados climáticos verificados nos respectivos horários de aplicação do herbicida, nas duas épocas do ano. Jaboticabal-SP, 2000/2001

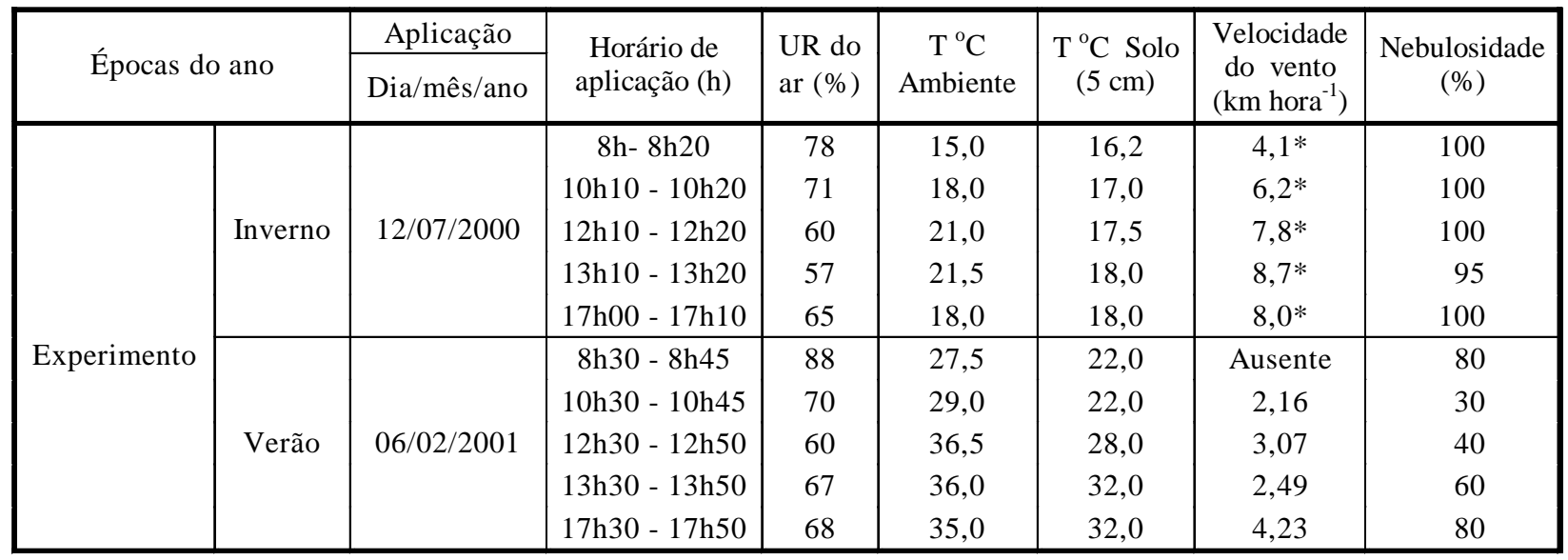

As diferenças de tempo para as chuvas simuladas foram conseguidas antecipando-se as aplicações dos herbicidas em seis, quatro, duas e uma hora. A chuva simulada foi feita de uma só vez, em área total. A aplicação do herbicida sem chuva foi feita cerca de uma hora após a simulação da chuva, quando as plantas apresentavam as lâminas foliares totalmente secas.

Foram realizadas avaliações visuais de eficácia dos herbicidas aos 17,26, 31 e 45 dias após a aplicação (DAA) dos tratamentos, no inverno, e aos 7, 14, 21 e 33 DAA, no verão. Em todas as avaliações, foram atribuídas, visualmente, as porcentagens de controle para as duas principais espécies de plantas daninhas, em que nenhum controle equivaleu à nota zero e controle total, à nota cem. Além das avaliações gerais da comunidade infestante, também foi quantificada a massa das plantas recémcolhidas (verdes) aos 41 DAA (inverno) e 33 DAA (verão) e, posteriormente, a massa seca. Para isso, as plantas foram cortadas rente ao solo, utilizando-se de um quadrado para amostragem de 0,75 x 0,75 m. Logo após a coleta, pesou-se o material coletado, no local, para obter os dados de massa recém-colhida. A seguir, o material foi colocado em sacos de papel e levado para estufa de circulação forçada de ar a $65{ }^{\circ} \mathrm{C}$, onde permaneceu por sete dias. Em seguida, as amostras foram pesadas, para obtenção dos dados de massa seca.
Os dados foram submetidos à análise de variância pelo teste $\mathrm{F}$, e, onde a interação dos fatores foi significativa, procedeu-se ao desdobramento desta com aplicação do teste de Tukey. As análises foram realizadas com o auxílio do programa ESTAT, com as porcentagens transformadas em arc sen $\sqrt{ } \%$.

\section{RESULTADOS E DISCUSSÃO}

Na Tabela 4 são apresentados os resultados do teste $\mathrm{F}$ aplicado às médias das porcentagens de controle geral das plantas daninhas influenciadas por chuvas simuladas em diferentes períodos após a aplicação de glyphosate + adjuvantes. Pode-se notar que houve interação significativa entre os fatores estudados nas diferentes épocas de avaliação, durante o experimento de inverno. Os desdobramentos das interações significativas são apresentados nas Tabelas 5, 6, 7 e 8, para cada época de avaliação.

Os dados aos 17 dias após a aplicação (inverno) mostram insuficiência no controle das plantas daninhas mesmo nos tratamentos que receberam chuva após períodos superiores a seis horas. É importante ressaltar que o período de 17 dias é suficiente para que esse herbicida extermine plantas em épocas mais quentes do ano com ou sem adjuvantes. Assim, observase que os adjuvantes não melhoraram a absorção do herbicida pelas plantas. Segundo Wittwer (1963), citado por Durigan (1993), a 
uréia necessita de apenas 0,5 a 2,0 horas para ser absorvida pela folha, carregando conjuntamente grande parte do herbicida. Possivelmente esse comportamento da uréia não foi observado no inverno, devido ao fato de as plantas se encontrarem em menor atividade metabólica, como conseqüência da temperatura mais baixa nessa época do ano. Apesar de esse adjuvante ter como característica o rompimento de algumas ligações éster, éter e diéter da cutícula, pode ocorrer maior absorção de outros elementos que estiverem juntos com a uréia na mesma calda, em razão, obviamente, do aumento do espaço de entrada.

Tabela 4 - Resultados do teste F para médias das porcentagens de controle químico geral das plantas daninhas, influenciadas por chuvas simuladas em diferentes períodos após a aplicação de glyphosate + adjuvantes, no inverno. Jaboticabal-SP, 2000

\begin{tabular}{|c|c|c|c|c|}
\hline \multirow{2}{*}{ Fatores } & \multicolumn{4}{|c|}{ Controle } \\
\hline & 17 DAA & $26 \mathrm{DAA}$ & $31 \mathrm{DAA}$ & $45 \mathrm{DAA}$ \\
\hline Testemunhas $\mathrm{x}$ fator & $304,48 * *$ & $496,15 * *$ & $307,03 * *$ & $514,95 * *$ \\
\hline Adjuvantes (A) & $5,20 * *$ & $5,49 * *$ & $2,04^{\mathrm{NS}}$ & $5,49 * *$ \\
\hline Período livre de chuva (P) & $69,66 * *$ & $173,25 * *$ & $150,06 * *$ & $189,19 * *$ \\
\hline$A \times P$ & $7,83 * *$ & $7,09 * *$ & $5,09 * *$ & $9,60 * *$ \\
\hline $\mathrm{CV}(\%)$ & 11,74 & 9,20 & 11,70 & 9,03 \\
\hline
\end{tabular}

*significativo a $5 \%$ de probabilidade.

**significativo a $1 \%$ de probabilidade.

Tabela 5 - Médias das porcentagens de controle químico geral das plantas daninhas, atribuídas visualmente aos 17 DAA, no inverno, influenciadas por chuvas simuladas em diferentes períodos após a aplicação de glyphosate + adjuvantes. Desdobramento da interação (adjuvantes x período sem chuvas = A x P). Jaboticabal-SP, 2000

\begin{tabular}{|l|c|c|c|c|c|}
\hline \multirow{2}{*}{ Herbicida + adjuvante } & \multicolumn{5}{c|}{ Período livre de chuvas (h) } \\
\cline { 2 - 6 } & 1 & 2 & 4 & 6 & $>48$ \\
\hline glyphosate + uréia & a $9,5 * \mathrm{~B}$ & a $15,7 \mathrm{~A}$ & a $15,7 \mathrm{~A}$ & a $15,7 \mathrm{~A}$ & $\mathrm{bc} 18,7 \mathrm{~A}$ \\
glyphosate + óleo vegetal & a 7,0 D & bc 8,0 CD & ab 11,2 BC & a 14,5 B & ab 24,7 A \\
glyphosate + sulfato de amônio & a 5,5 C & ab $11,5 \mathrm{~B}$ & a 15,7 AB & a 18,2 A & c 15,0 AB \\
glyphosate & a 5,7 C & c 6,0 C & b 8,7 C & a 15,0 B & a 30,0 A \\
\hline dms para médias de períodos dentro de cada adjuvante $=4,71$ (transformado). \\
dms para médias de adjuvantes dentro de cada período $=4,43$ (transformado). \\
\hline
\end{tabular}

* Dados originais.

Obs.: Letras minúsculas do lado esquerdo e no sentido das colunas comparam as formulações dentro de cada período; letras maiúsculas do lado direito e no sentido das linhas comparam os períodos dentro de cada adjuvante.

Tabela 6 - Médias das porcentagens de controle químico geral das plantas daninhas, atribuídas visualmente aos 26 DAA, no inverno, influenciadas por chuvas simuladas em diferentes períodos após a aplicação de glyphosate + adjuvantes. Desdobramento da interação (adjuvantes x período sem chuvas = A x P). Jaboticabal-SP, 2000

\begin{tabular}{|l|c|c|c|c|c|}
\hline \multirow{2}{*}{ Herbicida + adjuvante } & \multicolumn{5}{c|}{ Período livre de chuvas (h) } \\
\cline { 2 - 6 } & 1 & 2 & 4 & 6 & $>48$ \\
\hline glyphosate + uréia & a 17,5* C & a 22,5 BC & ab 26,2 B & a 35,0 A & b 43,7 A \\
glyphosate + óleo vegetal & b 11,2 D & a 16,2 CD & c 18,7 BC & b 25,0 B & a 55,0 A \\
glyphosate + sulfato de amônio & ab 12,5 B & a 18,7 B & a 30,0 A & a 33,7 A & b 38,7 A \\
glyphosate & ab 12,5 D & a 18,7 CD & bc 21,2 C & a 36,2 B & a 60,0 A \\
\hline dms para médias de períodos dentro de cada adjuvante $=5,43$ (transformado). \\
dms para médias de adjuvantes dentro de cada período =5,10 (transformado). \\
\hline
\end{tabular}

* Dados originais.

Obs.: Letras minúsculas do lado esquerdo e no sentido das colunas comparam as formulações dentro de cada período; letras maiúsculas do lado direito e no sentido das linhas comparam os períodos dentro de cada adjuvante. 
Tabela 7 - Médias das porcentagens de controle químico geral das plantas daninhas, atribuídas visualmente aos 31 DAA, no inverno, influenciadas por chuvas simuladas em diferentes períodos após a aplicação de glyphosate + adjuvantes. Desdobramento da interação (adjuvantes x período sem chuvas = A x P). Jaboticabal-SP, 2000

\begin{tabular}{|l|c|c|c|c|c|}
\hline \multirow{2}{*}{ Herbicida + adjuvante } & \multicolumn{5}{c|}{ Período livre de chuvas (h) } \\
\cline { 2 - 6 } & 1 & 2 & 4 & 6 & $>48$ \\
\hline glyphosate + uréia & a 15,0*C & a 21,2 BC & a 30,0 B & b 27,5 B & c 45,0 A \\
glyphosate + óleo vegetal & a 15,0 C & a 15,0 C & a 22,5 BC & ab 31,2 B & b 60,0 A \\
glyphosate + sulfato de amônio & a 12,5 D & a 18,7 CD & a 27,5 BC & ab 37,5 B & bc 53,7 A \\
glyphosate & a 12,5 C & a 16,2 C & a 21,2 C & a 40,0 B & a 72,5 A \\
\hline dms para médias de período dentro de cada adjuvantes $=7,16$ (transformado). \\
dms para médias de adjuvantes dentro de cada período =6,73 (transformado).
\end{tabular}

* Dados originais.

Obs.: Letras minúsculas do lado esquerdo e no sentido das colunas comparam as formulações dentro de cada período; letras maiúsculas do lado direito e no sentido das linhas comparam os períodos dentro de cada adjuvante.

Tabela 8 - Médias das porcentagens de controle químico geral das plantas daninhas, atribuídas visualmente aos 45 DAA, no inverno, influenciadas por chuvas simuladas em diferentes períodos após a aplicação de glyphosate + adjuvantes. Desdobramento da interação (adjuvantes x período sem chuvas = A x P). Jaboticabal-SP, 2000

\begin{tabular}{|l|c|c|c|c|c|}
\hline \multirow{2}{*}{ Herbicida + adjuvante } & \multicolumn{5}{c|}{ Período livre de chuvas (h) } \\
\cline { 2 - 6 } & 1 & 2 & 4 & 6 & > \\
\hline glyphosate + uréia & a 28,7*C & a 32,5 C & a 37,5 C & b 50,0 B & c 67,5 A \\
glyphosate + óleo vegetal & a 30,0 B & a 30,0 B & a 31,2 B & c 33,7 B & b 80,0 A \\
glyphosate + sulfato de amônio & a 31,2 C & a 30,0 C & a 35,0 BC & b 46,2 B & c 63,7 A \\
glyphosate & a 26,2 C & a 25,0 C & a 30,0 C & a 62,5 B & a 91,2 A \\
\hline dms para médias de período dentro de cada adjuvante $=7,04$ (transformado). \\
dms para médias de adjuvantes dentro de cada período = 6,62 (transformado).
\end{tabular}

* Dados originais.

Obs.: Letras minúsculas do lado esquerdo e no sentido das colunas comparam as formulações dentro de cada período; letras maiúsculas do lado direito e no sentido das linhas comparam os períodos dentro de cada adjuvante.

Aos 26 DAA, no tratamento em que não houve chuva antes de 48 horas, destacaramse o herbicida isolado e o adicionado de óleo vegetal, diferindo estatisticamente dos demais. No entanto, quando houve chuva uma hora após a aplicação, a uréia e o sulfato de amônio igualaram-se com o glyphosate isolado, porém sem resultado satisfatório de controle.

Os resultados de controle geral da comunidade infestante continuaram abaixo do exigido para ser considerado satisfatório, o que se deu em função das chuvas simuladas e principalmente do frio, na avaliação feita aos 31 DAA (Tabela 7). Os percentuais variaram, considerando-se os adjuvantes e os períodos sem chuva, de 12,5 a $72,5 \%$. Com chuva simulada após seis horas da aplicação, atendendo à recomendação da firma produtora, eles variaram de 27,5 a $40 \%$, muito inferior ao que se deseja no campo (90-100\%) para esse tipo de herbicida.

Com base nos resultados da última avaliação, aos 45 DAA, pode-se trabalhar com a hipótese de ter havido ação prejudicial dos adjuvantes ao glyphosate durante o inverno. Nos tratamentos submetidos a um período livre de chuva superior a 48 horas, o resultado de controle obtido com glyphosate isolado $(91,2 \%)$ foi estatisticamente superior aos obtidos com a adição de adjuvantes. Essa diferença também pode ser notada no tratamento que foi submetido a um período sem chuva de seis horas, em que o glyphosate proporcionou $62,5 \%$ de controle, contra 50\% correspondente ao maior controle obtido por glyphosate + uréia. Apesar de outros autores, como Field \& Bishop (1988) 
e Reddy \& Sing (1992), relatarem que o período sem chuva, para a máxima atividade do glyphosate, pode ser reduzido com a adição de outro produto químico, os resultados apontam para o fato de que os adjuvantes colocados na calda mostraram-se inócuos diante do menor metabolismo das plantas e que a chuva exerce efeito negativo marcante nessa época do ano, mesmo quando simulada em período considerado suficiente pelas recomendações oficiais. Esses resultados estão de acordo com Masiunas \& Weller (1988), os quais afirmam que o glyphosate apresenta maior efeito fitotóxico em temperaturas mais elevadas e menor em temperaturas mais baixas, em função da absorção diferenciada. Pedrinho Junior et al. (2002), trabalhando com efeito da chuva simulada em duas épocas do ano sobre o desempenho do herbicida sulfosate e com diferentes formulações do herbicida glyphosate, também notaram acentuada diferença no controle da comunidade infestante quando compararam os resultados obtidos no período de inverno com os resultados obtidos, para as mesmas espécies daninhas, durante o verão.

Na Tabela 9 são apresentados os resultados do teste $\mathrm{F}$ para os fatores envolvidos com o controle químico geral das plantas daninhas, influenciados por chuva simulada em diferentes períodos após a aplicação de glyphosate + adjuvantes, e do teste de Tukey para as médias dos fatores isolados nas épocas em que não houve interações significativas, no verão. Apenas na avaliação feita aos 21 DAA houve interação significativa entre períodos sem chuva e a presença de adjuvantes na calda. Em todas as avaliações houve efeito negativo da chuva simulada sobre a ação do herbicida. Esses dados estão de acordo com Reddy \& Sing (1992), pois, segundo eles, os herbicidas utilizados em pós-emergência podem ter a ação comprometida em função da ocorrência de chuvas após a aplicação e o período mínimo sem chuva, para não afetar o controle, varia de herbicida para herbicida e de planta para planta.

Tabela 9 - Resultados do teste F aplicado às médias das porcentagens de controle químico geral das plantas daninhas, influenciadas por chuvas simuladas em diferentes períodos após a aplicação de adjuvantes + glyphosate, e do teste de Tukey para as médias dos fatores isolados nas épocas em que não houve interações significativas, no verão. JaboticabalSP, 2001

\begin{tabular}{|c|c|c|c|c|c|}
\hline & \multirow{2}{*}{ Fator } & \multicolumn{4}{|c|}{ Controle } \\
\hline & & 7 DAA & 14 DAA & $21 \mathrm{DAA}$ & 33 DAA \\
\hline \multicolumn{2}{|l|}{ Testemunha $\mathrm{x}$ fatores } & $157,95 * *$ & $120,13 * *$ & $510,08 * *$ & $242,06 * *$ \\
\hline \multicolumn{2}{|l|}{ Adjuvantes (A) } & $5,06 * *$ & $0,78 * *$ & $18,72 * *$ & $6,12 * *$ \\
\hline \multicolumn{2}{|c|}{ Período livre de chuva $(\mathrm{P})$} & $82,13 * *$ & $49,05 * *$ & $135,97 * *$ & $80,43 * *$ \\
\hline \multicolumn{2}{|l|}{$\mathrm{A} \times \mathrm{P}$} & $1,45 * *$ & $1,22^{\mathrm{NS}}$ & $2,99 * *$ & $1,25^{\mathrm{NS}}$ \\
\hline & $\mathrm{CV}(\%)$ & 16,31 & 18,70 & 9,07 & 13,17 \\
\hline \multirow{4}{*}{ Adjuvantes } & glyphosate + uréia & $19,2 \mathrm{AB}$ & $46,2 \mathrm{~A}$ & & $68,0 \mathrm{~A}$ \\
\hline & glyphosate + óleo vegetal & $15,4 \mathrm{C}$ & $46,5 \mathrm{~A}$ & & $54,2 \mathrm{~B}$ \\
\hline & glyphosate + sulfato de amônio & $20,5 \mathrm{~A}$ & $50,5 \mathrm{~A}$ & & $63,5 \mathrm{AB}$ \\
\hline & glyphosate & $16,7 \mathrm{BC}$ & $44,2 \mathrm{~A}$ & & $57,7 \mathrm{~B}$ \\
\hline dms a $5 \%$ (transformado) & & 3,11 & 6,48 & & 5,53 \\
\hline \multirow{5}{*}{ Período sem chuva (h) } & $1 \mathrm{~h}$ & (a) $9,3 \mathrm{C}$ & $31,8 \mathrm{C}$ & & $43,7 \mathrm{D}$ \\
\hline & $2 \mathrm{~h}$ & $9,8 \mathrm{C}$ & $31,8 \mathrm{C}$ & & $49,0 \mathrm{CD}$ \\
\hline & $4 \mathrm{~h}$ & $17,8 \mathrm{~B}$ & $45,6 \mathrm{~B}$ & & $60,9 \mathrm{~B}$ \\
\hline & $6 \mathrm{~h}$ & $14,6 \mathrm{~B}$ & $41,5 \mathrm{BC}$ & & $55,3 \mathrm{BC}$ \\
\hline & $>48$ & $38,1 \mathrm{~A}$ & $83,4 \mathrm{~A}$ & & $95,4 \mathrm{~A}$ \\
\hline dms a $5 \%$ (transformado) & & 3,70 & 7,71 & & 6,58 \\
\hline
\end{tabular}

* significativo a $5 \%$ de probabilidade. ${ }^{* *}$ significativo a $1 \%$ de probabilidade. ${ }^{(a)}$ Dados originais. 
Rodrigues (1994), citado por Carvalho (2000), afirma ser o glyphosate um herbicida bastante vulnerável à chuva, desde que esta ocorra pouco tempo após a aplicação, não dando condições para que se processe efetivamente a fase ativa na absorção, ficando o produto no chamado espaço livre aparente, na fase passiva da absorção. Nessas condições, pode ocorrer fácil lavagem, reduzindo bastante a concentração do herbicida nas folhas e, assim, a sua eficácia. Jakelaitis et al. (2001), Roman (2001) e Pedrinho Junior et al. (2002) observaram efeitos negativos, causados pela chuva simulada poucas horas após a aplicação de sulfosate e diferentes formulações de glyphosate, no controle de diferentes espécies daninhas.

Nesse caso, diferentemente do observado no experimento de inverno, as adições de uréia e sulfato de amônio potencializaram o efeito do herbicida desde o início (7 DAA) até o final (33 DAA) das avaliações. O controle das plantas daninhas ocorreu mais rapidamente nessa época do ano, mostrando que a temperatura mais alta auxilia no efeito do herbicida sobre as plantas. Esses resultados estão de acordo com os encontrados por Pedrinho Junior et al.
(2002), que obtiveram melhores resultados de controle no verão do que no inverno. Aos 14 DAA, no tratamento com período sem chuva maior que 48 horas, o controle foi semelhante ao obtido aos 45 DAA na estação mais fria. Na última avaliação, esse tratamento exibia percentual de controle $(95,4 \%)$ adequado para situações práticas. O mesmo não ocorreu em todos os tratamentos com chuva simulada.

Durigan (1993) explica que a uréia é uma das substâncias cujas moléculas atravessam com relativa facilidade a cutícula das folhas e, mesmo sem receber energia metabólica, passam do apoplasto para o simplasto foliar. Esse fenômeno tem sido atribuído à difusão facilitada, em que as moléculas difusíveis atravessam a plasmalema por energia de ativação. A difusão facilitada tem um $\mathrm{Q}_{10}$ alto, porque, a temperaturas mais elevadas, maior número de partículas adquire suficiente energia de ativação para se difundir em um dado tempo. Com base nessa explicação, é possível entender por que em baixas temperaturas a uréia não auxiliou o glyphosate em uma penetração mais rápida, resultado esse obtido no experimento do verão. O sulfato de amônio é um dos aditivos iônicos com grande velocidade de penetração

Tabela 10 - Média das massas frescas e secas, aos 45 DAA (inverno) e 30 DAA (verão), acumuladas com chuvas simuladas em diferentes períodos após a aplicação de glyphosate + adjuvantes. Jaboticabal-SP, 2000/2001

\begin{tabular}{|c|c|c|c|c|c|}
\hline & \multirow{2}{*}{ Fator } & \multicolumn{2}{|c|}{ Massa (kg) inverno } & \multicolumn{2}{|c|}{ Massa $(\mathrm{kg})$ verão } \\
\hline & & fresca & seca & fresca & seca \\
\hline \multirow[t]{2}{*}{$\mathrm{F}$} & $\begin{array}{l}\text { Testemunha x fatores } \\
\text { Adjuvantes (A) } \\
\text { Período livre de chuva (P) } \\
\text { A x P }\end{array}$ & $\begin{array}{c}41,49 * * \\
0,90^{\mathrm{ns}} \\
6,23^{* *} \\
0,39^{\mathrm{ns}}\end{array}$ & $\begin{array}{c}10,77^{* *} \\
1,37^{\mathrm{ns}} \\
0,70^{\mathrm{ns}} \\
0,51^{\mathrm{ns}} \\
\end{array}$ & $\begin{array}{l}8,18^{* *} \\
0,83^{\mathrm{ns}} \\
2,59^{*} \\
1,62^{\mathrm{ns}}\end{array}$ & $\begin{array}{c}23,13^{* *} \\
1,19^{\mathrm{ns}} \\
2,25^{\mathrm{ns}} \\
0,95^{\mathrm{ns}}\end{array}$ \\
\hline & $\mathrm{CV}(\%)$ & 43,49 & 39,29 & 48,52 & 48,52 \\
\hline Adjuvantes & $\begin{array}{l}\text { glyphosate + uréia } \\
\text { glyphosate + óleo vegetal } \\
\text { glyphosate + sulfato de amônio } \\
\text { glyphosate }\end{array}$ & $\begin{array}{l}0,60 \mathrm{~A} \\
0,69 \mathrm{~A} \\
0,69 \mathrm{~A} \\
0,70 \mathrm{~A}\end{array}$ & $\begin{array}{l}0,18 \mathrm{~A} \\
0,20 \mathrm{~A} \\
0,20 \mathrm{~A} \\
0,21 \mathrm{~A}\end{array}$ & $\begin{array}{l}0,31 \mathrm{~A} \\
0,36 \mathrm{~A} \\
0,34 \mathrm{~A} \\
0,30 \mathrm{~A}\end{array}$ & $\begin{array}{l}0,31 \mathrm{~A} \\
0,36 \mathrm{~A} \\
0,34 \mathrm{~A} \\
0,30 \mathrm{~A}\end{array}$ \\
\hline dms a $5 \%$ & & 0,27 & 0,07 & 0,08 & 0,08 \\
\hline $\begin{array}{l}\text { Período sem } \\
\text { chuva (h) }\end{array}$ & $\begin{array}{l}1 \mathrm{~h} \\
2 \mathrm{~h} \\
4 \mathrm{~h} \\
6 \mathrm{~h} \\
>48\end{array}$ & $\begin{array}{l}0,91 \mathrm{~A} \\
0,82 \mathrm{AB} \\
0,71 \mathrm{ABC} \\
0,58 \mathrm{AB} \\
0,40 \mathrm{C}\end{array}$ & $\begin{array}{l}0,23 \mathrm{~A} \\
0,21 \mathrm{~A} \\
0,21 \mathrm{~A} \\
0,19 \mathrm{~A} \\
0,18 \mathrm{~A}\end{array}$ & $\begin{array}{l}0,33 \mathrm{~A} \\
0,36 \mathrm{~A} \\
0,31 \mathrm{~A} \\
0,37 \mathrm{~A} \\
0,28 \mathrm{~A}\end{array}$ & $\begin{array}{l}0,33 \mathrm{~A} \\
0,36 \mathrm{~A} \\
0,31 \mathrm{~A} \\
0,37 \mathrm{~A} \\
0,28 \mathrm{~A}\end{array}$ \\
\hline dms a $5 \%$ & & 0,32 & 0,08 & 0,10 & 0,10 \\
\hline
\end{tabular}

$*$ significativo a $5 \%$ de probabilidade. $* *$ significativo a $1 \%$ de probabilidade. 
na epiderme das folhas, mas tem comportamento diferenciado em diferentes níveis de $\mathrm{pH}$, o que pode muitas vezes impedir que ele atue com a mesma velocidade de absorção em todos os casos.

Na Tabela 10 são apresentadas as médias das massas fresca e seca das plantas daninhas, nos experimentos de inverno (45 DAA) e verão (30 DAA), respectivamente. No verão, em razão do melhor desempenho, as massas amostradas nas parcelas não apresentaram diferenças significativas e não indicaram as variações de controle proporcionadas pela situação precoce da chuva. A massa fresca foi maior onde o intervalo sem chuva foi de uma hora, comparada à obtida no tratamento em que o intervalo mínimo foi de 48 horas, porém sem diferença estatística. No entanto, no inverno, as diferenças de massa fresca foram mais evidentes, diferenciando estatisticamente o período que recebeu chuva uma hora após a aplicação dos tratamentos que receberam chuva após período superior a seis horas da aplicação.

Com base nos resultados apresentados, pode-se concluir que a utilização de adjuvantes na calda de pulverização não beneficiou o desempenho do glyphosate no inverno e que a adição de uréia (50 $\mathrm{g} \mathrm{L}^{-1}$ de calda) é uma boa alternativa para a melhora do controle de plantas daninhas no verão, em situações sujeitas à chuva após a aplicação.

\section{LITERATURA CITADA}

BAIRD, D. D. et al. Introduction of a new broad spectrum postemergent herbicide class with utility for herbaceous perennial weed control. Proc. N. Cent. Weed Contr. Conf., v. 26, p. 64-68, 1971.

BLANCO, H. G. et al. Observações sobre o período crítico em que as plantas daninhas competem com a soja (Glycine $\max ($ L.) Merrill). O Biológico, v. 39, p. 31-35, 1973.

CARVALHO, J. C. Interações entre glyphosate e oxyfluorfen, aplicados em pós-emergência, no controle de plantas daninhas. Botucatu: Universidade Estadual de São Paulo, 2000. 119 p. Tese (Doutorado em Agronomia) Universidade Estadual de São Paulo, 2000.

CENTURION, J. F. Caracterização e classificação dos solos da Faculdade de Ciências Agrárias e Veterinárias de Jaboticabal. Jaboticabal: Universidade Estadual Paulista, 1998. 84 p. Tese (Livre Docência) - Universidade Estadual Paulista, 1998.
DURIGAN, J. C. Efeito de adjuvantes na calda e do estádio de desenvolvimento das plantas, no controle do capimcolonião (Panicum maximum) com glyphosate. Planta Daninha, v. 10, n.1/2, p. 39-44, 1992.

DURIGAN, J. C. Efeito de adjuvantes na aplicação e eficácia dos herbicidas. Jaboticabal, Fundação de Estudos e Pesquisas em Agronomia, Medicina Veterinária e Zootecnia, 1993. $42 \mathrm{p}$.

FAWCETT, R. S.; DAVIS, H. Effect of enviroment on glyphosate activity in quackgrass. Proc. N. Cent. Weed Contr. Conf., v. 31, p. 159-160, 1976.

FIELD, R. J.; BISHOP, N. G. Promotion of stomatal infiltration os glyphosate by an organosilicone surfactent reduces the critical rainfall period. Pesticide Sci., v. 24, p. 55-62, 1988.

HEAP, I. M. The occurrence of herbicide resistant weeds worldwide. Pesticide Science, v. 51, n. 2, p. 235-243, 1997.

JAKELAITIS, A. et al. Controle de Digitaria horizontalis pelos herbicidas glyphosate, sulfosate e glyphosate potássico submetidos a diferentes intervalos de chuva após a aplicação. Planta Daninha, v. 19, n. 2, p. 279-286, 2001.

KRUSE, N. D.; TREZZI, M. M.; VIDAL, R. A. Herbicidas inibidores da EPSPs: Revisão de literatura. R. Bras.

Herbic., v. 1, n. 2, p. 139-146, 2000.

MASIUNAS, J. B.; WELLER, S. C. Glyphosate activity in potato (Solanum tuberosum) under different temperature regimes and light levels. Weed Sci., v. 36, p. 137-140, 1988.

PEDRINHO JUNIOR, A. F. F. Influência da chuva simulada na eficácia agronômica do herbicida glyphosate, sobre diferentes formulações, concentrações e adjuvantes, no inverno e no verão. Jaboticabal: Universidade Estadual de São Paulo, 2001. 149 p. (Trabalho de Graduação).

PEDRINHO JUNIOR, A. F. F. et al. Momento da chuva após a aplicação e a eficácia dos herbicidas sulfosate e glyphosate aplicados em diferentes formulações. Planta Daninha, v. 20, n. 1, p. 115-123, 2002.

POOVAIAH, B. W.; LEOPOLD, A. C. Hormone-solute interactions in the lettuce hypocotyl hook. Plant Physiol., v. 54, n. 3, p. 289-293, 1974.

REDDY, K. N; SINGH, M. Organosilicone adjuvant effects on glyphosate efficacy and rainfastness. Weed Technol., v. 6, n. 2 , p. $361-365,1992$.

ROMAN, E. S. Influência de chuva simulada na eficácia de diferentes formulações e doses de glyphosate. R. Bras.

Herbic., v. 2, n. 3, p. 119-124, 2001.

RUITER, H.; MAINEN, E. Influence of water stress and surfactant on the efficacy, absorption, and translocation of glyphosate. Weed Sci., v. 46, n. 3, p. 289-296, 1998. 